Observatório de
Inovação do Turismo

Revista Acadêmica

ISSN 1980-6965

www.ebape.fgv.br/revistaoit
BRASIL

BRASIL

Sensacional!

\title{
Inovação como instrumento de desenvolvimento de atividade turística
}

\section{Innovation as an instrument of development in tourism}

\author{
Vanessa de Oliveira Menezes \\ Sieglinde Kindl da Cunha
}

\begin{abstract}
Resumo
Este estudo pretende ser um ensaio teórico sobre o desenvolvimento da inovação, relacionando-o com a atividade turística em termos mundiais. Para isso, foi realizada uma pesquisa de cunho bibliográfico utilizando autores da Teoria da Inovação e escritores brasileiros e internacionais sobre o Turismo. A partir da pesquisa bibliográfica é possível afirmar que as inovações se deram no contexto de cinco revoluções tecnológicas, sendo elas: Revolução Industrial; Era do Vapor e dos Trilhos de Ferro; Era do Aço, da Eletricidade, da Engenharia Pesada; Era do Óleo, do Automóvel e da Produção em Massa; e a Era da Informação e Telecomunicações. A pesquisa permitiu observar que essas revoluções introduziram novas tecnologias que foram capazes de modificar as práticas em cada um dos períodos destacados, e, embora essas inovações não tenham sido criadas para a atividade turística especificamente, muitas delas foram absorvidas e utilizadas dentro do setor.
\end{abstract}

Palavras-chave: Turismo; Inovação; Revoluções Tecnológicas; Relação entre Inovação e Turismo.

Artigo recebido em 26 de março de 2013 e aceito em 17 de julho de 2013. 


\begin{abstract}
:
This study intends to be a theoretical essay on the development of innovation, linking it with tourism globally. To do so, bibliographical research was done with authors of Innovation Theory and Brazilian and International researchers in tourism. From the bibliographical research it is possible to say that the innovations took place in the context of five technological revolutions, which are: Industrial Revolution, Age of Steam and Railroads; Age of Steel, Electricity, Heavy Engineering; Age of Oil, Automobile and Mass Production; and Age of Information and Telecommunications. It was possible to observe from the research that these revolutions introduced new technologies that were able to modify the practices in each of the periods highlighted, and although these innovations have not been created specifically for the tourism activity, many of them were absorbed and used within the industry.
\end{abstract}

Key words: Tourism; Innovation; Technological Revolutions; Relation between Innovation and Tourism.

\title{
1. Introdução
}

A inovação é uma constante no mundo moderno. É possível observar que a cada dia estádisponível no mercado um número maior de produtos e serviços que facilitam a vida do homem. Mas a inovação não é uma realidade recente. Ela está presente na história mundial há muito tempo, e por meio dela muitos setores econômicos se desenvolveram.

O Turismo é um dos setores econômicos atuais mais relevantes em todo o mundo (OMT, 2001). Os autores da área não são unânimes ao definir a data precisa de início da atividade (BARRETTO, 1995), contudo ela se transformou, certamente, em um setor maduro e global. É um fenômeno social que se utiliza de outras áreas paraseu funcionamento. Eé com base nesta realidade que surge como problemática: qual é a relação das revoluções tecnológicas com o desenvolvimento da atividade turística?

A partir deste problema, o objetivo central deste estudo é apresentar um ensaio teórico sobre o desenvolvimento da inovação, relacionando-o com a atividade turísticaem nível mundial.

Este estudo está ancorado na abordagem tecnicista da inovação em serviços, na qual Gallouj (1998) afirma que a inovação no setor de serviços está baseada na adoção de inovações tecnológicas desenvolvidas, a princípio, para o setor de produção. Estas inovações são apenas absorvidas e adaptadas às necessidades das empresas de serviços, neste caso o setor turístico. De acordo com Vargas e Zavislak (2002), esta é a abordagem mais empregada em estudos relacionados à inovação em serviços.

A iniciativa para a elaboração deste trabalho surgiu de um interesse neste enfoque de estudo, mas também de uma deficiência em pesquisas científicas que abordem a aplicação da inovação 
dentro da atividade turística. Hjalager (2002, 2010), Peters e Pikkemaat (2005) e Chai (2005) são alguns dos poucos pesquisadores que trabalham a temática em nível mundial. No Brasil, Klement (2007), Zdepskiet al. (2012), Figueiredo et al. (2010) e Brunelliet al. (2012) também trataram da inovação no turismo, centrando-se, contudo, em estudos de caso. A relevância deste trabalho, portanto, está no fato de trazer uma nova contribuição à temática e ampliar o escopo relacionado à Teoria da Inovação, principalmente ao abordar sua relação com a atividadeturística.

Esta pesquisa caracteriza-se como sendo de natureza qualitativa, de propósito exploratório e descritivo, por meio da coleta de dados secundários. Foi realizada uma pesquisa de cunho bibliográfico, utilizando-se autores reconhecidos na questão da historiografia da inovação, como Freeman e Soete (2008), Landes (1998), Mokyr (1990), entre outros, além de escritores brasileiros e internacionais ligados ao turismo, como Rejowski e Solha (2002), Ignarra (2001), Barretto (1995), Lickorish e Jenkins (2000), Boyer (2003), entre outros.

O estudo desenvolve uma abordagem histórica da inovação, destacando as cinco revoluções tecnológicas vivenciadas pelo homem, a fim de contribuir para o entendimento das relações entre a inovação e o turismo.

O primeiro item, que constitui esta breve introdução, apresenta o tema ao leitor, contextualizando o assunto e explicitando o objetivo, a metodologia e a abordagem adotada. Asegunda seção traz a parte conceitual, em que se apresentam a diferença entre invenção e inovação, os tipos de inovação, mudança tecnológica, ciclo de vida, revoluções e paradigmas tecnológicos. Estaparte do texto auxiliará no entendimento a respeito da forma como surgem as inovações e mostrará que estas transformam não só a economia comotambém o ambiente e a sociedade.

As seções seguintes apresentam as revoluções tecnológicas em si.Nos itens3 e 4 destacam-se duas revoluções em conjunto, a saber: a Revolução Industrial e aEra do Vapor e dos Trilhos de Ferro, primeiramente, e, na sequência, a Era do Aço, da Eletricidade, da Engenharia Pesada, bem como aEra do Óleo, do Automóvel e da Produção em Massa. Elas foram dispostas desta maneira por estarem inter-relacionadas. Já o item 5 traz uma única revolução, a Era da Informação e Telecomunicações, em que será possível perceber que ainda estamos vivenciando este período da história, havendo portanto muitas transformações que se encontram em evolução nesta onda de inovações. No contexto de cada uma das revoluções serão apresentados panoramas macroambientais, principais inovações, seus paradigmas e contribuições para a atividade turística global.

De posse dessas informações, o estudo trará as considerações finais, em que se estabelece a relação das discussões trazidas no texto, na qual foi possível observar que as revoluções tecnológicas introduziram novas tecnologias, capazes de modificar as práticas em cada um dos períodos destacados, e que, embora essas inovações não tenham sido destinadas para a atividade turística especificamente, muitas delas foram absorvidas e utilizadas dentro do setor. 


\section{Bases Conceituais da Inovação}

A invenção é algo que sempre esteve presente na vida do homem. Desde a criação da roda até a moderna robótica, todos esses novos produtos ou processos foram inventados para facilitar as atividades do dia a dia. Porém, há uma diferença entre invenção e inovação. De acordo com Perez (2004), invenção é a criação de um novo produto ou processo, sendo que esta descoberta ocorre dentro da própria ciência. Ela surge em qualquer momento e nem sempre chega a ser uma inovação. Inovação, por sua vez, é um feito econômico; é o mercado que decidirá se irá aceitar ou não esta criação. É importante ressaltar, ainda, que uma inovação só poderá se transformar em um fenômeno global se houver a difusão em massa desta nova tecnologia.

De acordo com Smith (2000), a inovação é fundamental para a competitividade entre as organizações e não constitui um fenômeno marginal, uma vez que é nela que se apoia o crescimento econômico em nível nacional.

Grande parte das inovações traz um fluxo contínuo de mudanças incrementais, quer dizer, melhorias sucessivas em produtos e/ou processos que já estão à disposição das pessoas. Além das inovações incrementais existem também as inovações radicais, aquelas que introduzem no mercado um novo produtoou processo. Perez (2004) afirma que esta última é um ponto de partida, que serve de início para novas trajetórias técnicas. Pode ser introduzida a qualquer momento e é capaz de desenvolver novas indústrias.Cabe destacar, contudo,que o surgimento de inovações não é um fenômeno aleatório, e nenhuma evolução ocorre isolada. A inovação é um processo coletivo e sistêmico que envolve diferentes agentes de mudança - fornecedores, distribuidores, consumidores, entre outros. (PEREZ, 2004).

Em muitas situações, a inovação está ligada à mudança tecnológica. Com relação a esta afirmativa, Mokyr (1990) destaca que a mudança tecnológica na maioria das vezes apareceu como consequência de um processo sistemático de pesquisa e desenvolvimento. Mas, de acordo com Rosenberg (2006), a evolução desta mudança é inseparável da história da própria civilização. Ela não se deve a uma razão em particular, e sim a muitas situações,visão esta corroborada por Mokyr (1990).

Toda inovação possui um ciclo de vida. De acordo com Perez (2009), ela aparece lentamente, no início, quando produtores, designers, distribuidores e consumidores se familiarizam com os novos processos. Rápida e intensamente, ela se transforma em um design dominante até chegar à maturidade. Mas é importante ressaltar que a maturidade não significa necessariamente a morte de uma tecnologia. Neste caminho, podem ser inseridos novos usos ou abordagens que fazem com que esta inovação continue vigente.

A história do homem, especialmente após a Idade Média, foi marcada por várias revoluções tecnológicas. Segundo Perez (2004, p. 26), revolução tecnológica é a "difusão de um conjunto 
de tecnologias genéricas, capaz de transformar e rejuvenescer a praticamente todas as indústrias existentes, junto com a criação de um grupo de novas indústrias dinâmicas no centro de sistemas tecnológicos radicalmente novos". Ela modifica a prática em todos os setores e traz um conjunto de novas indústrias, um conjunto de tecnologias genéricas de grande aplicabilidade e novos princípios organizacionais (PEREZ, 2004).Para que essa revolução ocorra, entretanto,são necessários toda uma infraestrutura e o aparato institucional para dar suporte a essa nova realidade.

Segundo Perez (2009), entre 1770 e 2000 houve cinco sucessivas revoluções tecnológicas. A primeira é conhecida como Revolução Industrial, tendo seu auge a partir de 1771 na Grã-Bretanha; a segunda é a Era do Vapor e dos Trilhos de Ferro, que surgiu também na Grã-Bretanha a partir de 1829 e logo se espalhou para os Estados Unidos; a terceira é a Era do Aço, da Eletricidade e da Engenharia Pesada, que surgiu nos Estados Unidos a partir de 1875, e se espalhou posteriormente para a Alemanha; a quarta é a Era do Óleo, do Automóvel e da Produção em Massa, que se desenvolveu nos Estados Unidos em 1908, chegando posteriormente a países da Europa como a Alemanha; e,por último, tem-se a Era da Informação e Telecomunicações, que também surgiu nos Estados Unidos na década de 1970, estendendo-se para a Europa e Ásia.

Perez (2009) afirma que cada revolução tecnológica propõe um paradigma dominante por um longo período. Paradigma é "[...] uma lógica coletivamente compartilhada na convergência do potencial tecnológico, de custos relativos, de aceitação do mercado, da coerência funcional e dos outros fatores" (p.3).E é neste processo que entra a teoria de Schumpeter (1961) de destruição criativa, pois no processo de revolução tecnológica as inovações destroem ou renovam antigos modelos de negócios,fazendo-se necessário implantar novas ideias, comportamentos e formas de agir que se adaptem à nova realidade. Este novo paradigma, contudo, requer tempo para ser absorvido e encontra resistência e conflito em seu ambiente.

Para facilitar o entendimento de cada uma dessas revoluções tecnológicas, sua ação nos paradigmas vigentes e sua influência na atividade turística, elas são apresentadas a seguir de forma mais detalhada.

\section{A Revolução Industrial e a Era do Vapor e dos Trilhos de Ferro}

De acordo com Freeman e Soete (2008), a Revolução Industrial está relacionada às inovações implantadas na atividade industrial daquele período. Estas mudanças técnicas tiveram seu auge na Grã-Bretanha, no final do século XVIII e início do século XIX.

Landes (1998) afirma que a Revolução Industrial ocorreu com base em três princípios: a substituição do trabalho do homem por máquinas - que eram mais rápidas, regulares, precisas e incansáveis; a substituição de fontes animadas por fontes inanimadas de força, em especial, 
a invenção da máquina para converter calor em trabalho, abrindo, desta forma, uma grande oferta de energia; e o uso de novas e muito mais abundantes matérias-primas, em particular a substituição de substâncias vegetais ou animais por materiais minerais e, posteriormente, artificiais.

Smith (2003), ao tentar explicar porque o padrão de vida na Grã-Bretanha era melhor que o de outros países europeus, destacou o papel da indústria da transformação e do comércio sobre outras atividades econômicas. Para ele, a divisão do trabalho na manufatura facilitou o uso de novas máquinas, a aquisição de habilidades pelos operários e a abertura de mercados, além da redução de barreiras ao comércio dentro dos países e entre eles. Esta última fez com que os produtos industriais competissem, aumentando seus mercados e alcançando economias de escala para seus produtos, proporcionando um aumento na lucratividade.

Os estudiosos de modo geral concordam que a Revolução Industrial foi um marco na história da humanidade. Mas alguns autores, como List (1841, apud LANDES, 1998), criticam Smith, afirmando que ele subestimou a importância da ciência e da tecnologia e superestimou a importância da divisão do trabalho. Já Landes (1998) ressalta que alguns economistas modernos acreditam que a Revolução Industrial tenha sido mais evolucionária que revolucionária, pois, refazendo os cálculos do desenvolvimento daquele período, os resultados apresentados pelos pesquisadoresforam extremamente modestos.

Tanto Landes (1998) como Freeman e Soete (2008) concordam que não é possível datar com precisão quando a Revolução Industrial se iniciou, pois algumas situações importantes já vinham acontecendo há muitos anos. Porém, as mudanças mais significativas ocorreram a partir de 1780.

A indústria têxtil, algodoeira e, em menor escala, a de metalurgia de ferro foram os setores econômicos que mais progrediram. As melhorias e invenções resultaram na diminuição do preço, no crescimento das exportações em decorrência destes novos valores, no aumento da produção, os quais transformaram os produtos britânicos nos mais competitivos do mundo. Porém, este crescimento só se deu por estar intimamente ligado ao avanço técnico. Landes (1998, p.207) complementa esta afirmação quando diz que "[...] a economia e o conhecimento estavam crescendo com rapidez bastante para gerar um contínuo fluxo de melhorias".

Todos os autores econômicos concordam que as invenções foram importantes para acelerar o crescimento da Grã-Bretanha, mas há divergências com relação às principais invenções. Alguns afirmam que elas foram simples, enquanto outros estudiosos dizem que elas vieram do gênio individual e do brilho científico, muito mais do que de um processo social contínuo (FREEMAN e SOETE, 2008). Segundo estes autores, essas divergências ocorrem porque até hoje existe um grande rol de invenções e inovações e a maioria é resultado das melhorias incrementais de produtos e processos já existentes. Para Von Tunzelmann (1999, apud FREEMAN e SOETE, 2008), o que induzia à inovação era a economia de tempo, e as economias fixas e de giro, de trabalho e de recursos naturais foram resultados indiretos destasituação. 
O mercado de capital formal e a classe dos ricos proprietários de terra tiveram um papel importante no financiamento de obras relacionadas à infraestrutura. A burguesia industrial também investiu em infraestrutura pública, e sua força era tão grande que ela possuía influência política nas decisões (FREEMAN e SOETE, 2008).

Um dado interessante a destacar é que a inovação veio de todas as classes sociais e de todas as regiões britânicas. De acordo com os referidos autores, estes visionários foram importantes, pois tinham pontos de vista nãoconformistas e racionalistas.

O auge do crescimento da indústria têxtil foi de 1780 a 1800; após este período, embora tenha havido crescimento no setor, este se deu em um ritmo mais lento. As invenções, contudo, ainda segundo esses autores, continuaram a ocorrer em todo o século XIX.

Com o crescimento da produção, surgiu a necessidade de um meio de transporte mais rápido e seguro. Utilizando a tecnologia já existente, foi criada a primeira locomotiva, em 1814. Em pouco tempo, surgiram os modelos a vapor e as primeiras estradas de ferro. Este modal passou a ser o meio de transporte mais importante e representativo do continente e trouxe um novo ciclo de desenvolvimento para a Grã-Bretanha. Surge então a Era do Vapor e dos Trilhos de Ferro. Perez (2009) menciona que as principais tecnologias desenvolvidas neste período foram: os motores a vapor e máquinas - fabricados em ferro e movidos a carvão; o setor de ferro e minas de carvão, que passou a desempenhar um papel central no crescimento; a construção de ferrovias, a produção de material circulante e o uso da máquina a vapor em outras indústrias, inclusive no setor têxtil.

A partir desse período, muitas invenções e inovações foram difundidas em outros países, como os Estados Unidos, mas ainda havia um predomínio britânico. Esse predomínio, para Mass e Lazonick (1990, apud FREEMAN e SOETE, 2008), se deu pela sustentada vantagem competitiva, devido aos hábitos e trabalho fabril e às habilidades acumuladas da força de trabalho.

Essa nova realidade trouxe diferentes paradigmas tecnoeconômicos. Perez (2009) destaca que,no contexto da Revolução Industrial, esse novo paradigma eleva a produtividade sem precedentes anteriores e induz à mecanização e à economia de tempo. Já com relação à Era do Vapor e dos Trilhos de Ferro, a autora ressalta grandes transformações socioeconômicas, como economias de aglomeração, criação de cidades industriais e mercados nacionais; centros de poder com as redes nacionais; escala como sinônimo de progresso; máquinas que fabricam novas máquinas e movimentos interdependentes - de máquinas e meios de transporte.

A revolução tecnológica não traz novas mudanças apenas para a economia, mas para a sociedade como um todo. Em ambos os períodos, foi possível verificar uma transformação no cotidiano das pessoas. Grande parte da população rural passa a viver nas grandes cidades em busca de novas oportunidades de emprego; há um novo ritmo de vida, mais dinâmico e controlado pelo trabalho, e surge uma diferente cultura, adequada à nova realidade. Por outro lado, Landes (1998, p.216) alerta ao afirmar que a Revolução Industrial também teve aspectos negativos. De acordo 
com o autor, "as conseqüências desses avanços foi um crescente hiato entre os países industriais modernos e os retardatários, entre ricos e pobres". A Revolução Industrial foi um paradoxo, pois de um lado aproximou o mundo, mas por outro fragmentou o globo ao separar os vencedores dos perdedores (LANDES, 1998).

A atividade turística nesse período era ainda amadora e praticada apenas por uma pequena parcela da sociedade, ou, como denomina Boyer (2003), uma "minoria privilegiada". Mas, Rejowski, Yasoshima Stigliano e Silveira (2002) e Gurría Di-Bella (1991) argumentam que a Revolução Industrial criou condições que facilitaram a popularização das viagens turísticas, como o surgimento de uma nova camada social, a classe média, o aumento do tempo livre e a procura por viagens de lazer. Tais condições foram intensificadaspouco depois com o uso da máquina a vapor, um meio de transporte prático e que diminuía as distâncias.

Em 1841, um inglês vendedor de bíblias chamado Thomas Cook teve uma ideia empreendedora ao comprar bilhetes de trem e revendê-los a 570 pessoas para queelas pudessem participar de um evento em Lougbouroug, no interior da Inglaterra. Esta foi a primeira viagem organizada do mundo e, a partir desta iniciativa, o turismo passou a ser uma atividade comercial (IGNARRA, 2001; BARRETTO, 1995; GURRÍA DI-BELLA, 1991; CÂNDIDO e VIERA, 2003). Utilizando o transporte ferroviário como base, outros empreendedores organizaram suas próprias viagens com fins turísticos, surgindo assim as primeiras agências de viagem.

A máquina a vapor não estava presente apenas nas locomotivas; ela era utilizada também nas navegações,transformando as viagens intercontinentais em produtos viáveis comercialmente (IGNARRA, 2001; BARRETTO, 1995). Aproveitando esse novo nicho de mercado, a Agência Abreu, empresa turística fundada na cidade de Porto, Portugal, em 1840, e presente no mercado até hoje, também passou a agenciar passagens de navios para os emigrantes europeus que pretendiam começar uma nova vida na América do Sul (REJOWSKI e PERUSSI, 2008). Portanto, é a partir deste período que o turismo começa a ser visto como uma atividade profissional. Surgem outros empreendedores europeus no ramo que passam a oferecer produtos diferenciados, atendendo às demandas vigentes, e,assim, o turismo começa a vivenciar os novos desafios da modernidade.

\section{A Era do Aço, da Eletricidade e da Engenharia Pesada, e a Era do Óleo, do Automóvel e da Produção em Massa}

Estes períodos estão estreitamente relacionados com o desenvolvimento econômico e a evolução do processo técnico nos Estados Unidos nos séculos XIX e XX. Relativamente ao desenvolvimento da tecnologia, Freeman e Soete (2008) afirmam que alguns países podem ser mais ou menos favoráveis com relação ao avanço da ciência, e que esta é a responsável pelas 
próximas revoluções econômicas mundiais."Os Estados Unidos tomou uma posição de destaque no desenvolvimento econômico no decorrer do século XIX, quando assumiu a liderança tecnológica mundial onde a economia e a produtividade cresceram de forma mais significativa que em outros países." (FREEMAN e SOETE, 2008, p.102).

Segundo esses autores, o crescimento tardou um pouco pela falta de infraestrutura, contudo o desenvolvimento do transporte ferroviário e as novas tecnologias do século XIX fizeram com que o país avançasse. A princípio, a tecnologia aplicada na América do Norte era trazida da Europa, mas, com o tempo, os americanos passaram a criar seus próprios processos e produtos, passando a apoiar as invenções e inovações técnicas.

Os Estados Unidos foram em parte colonizados por imigrantes, e estes cidadãos tiveram que se adaptar às condições do novo território. O uso da terra incentivou o surgimento da pesquisa agrícola, contando com o apoio do governo. Para Freeman e Soete (2008), a abundância de terras, a expansão para o Oeste e a destruição das civilizações nativas ou seu confinamento em pequenos territórios foram situações que favoreceram o desenvolvimento econômico capitalista do país, porém a distribuição de renda e de riqueza entre os imigrantes brancos era relativamente igualitária. O sul, com sua economia escravista, em um primeiro momento não apresentava o mesmo desenvolvimento do restante do país, fato superado após a Guerra Civil.

Abramovitz e David (1994, apud FREEMAN e SOETE, 2008) afirmam que a abundância de recursos e o grande e homogêneo mercado interno foram fatores que contribuíram para as altas taxas de crescimento econômico do país. Oelevado custo da mão de obra norte-americana forçou os Estados Unidos a investir na produção mecanizada e padronizada. O aço e a eletricidade tornaram-se os setores de maior crescimento no país entre 1880 e 1913 (FREEMAN e SO$E T E, 2008)$. Os autores afirmam também que os empresários se destacaram no aumento da escala dos processos de produção e na inovação, seja dos maquinários ou dos sistemas produtivos. O processo de oligopolização e a produção em massa estão diretamente ligados ao desenvolvimento da infraestrutura de transporte e de comunicação. Ainda de acordo com os autores,o aço, um dos pilares do desenvolvimento econômico americano, tinha custos mais baixos e poderia ser usado na fabricação de diversos novos produtos, instrumentos e processos, sobretudo nas áreas de maquinário, engenharia e construção. Com a pesquisa, o aço tornou-se um metal mais resistente e necessário em todas as áreas, inclusive na indústria alimentícia e na fabricação de objetos triviais, como a bicicleta. Perez (2009) destaca que o aço esteve presente em toda a onda de inovações vivenciadas neste período da história americana.

Além do aço, outra inovação importante foi o uso da energia elétrica. A princípio, esta energia estava ligada às telecomunicações, com o telégrafo elétrico; logo estendeu seu uso ao telefone e aos faróis marítimos. Para Freeman e Soete (2008), embora a eletricidade já viesse sendo usada para facilitar a vida das pessoas, foi só a partir do desenvolvimento de uma série de novos 
inventos e inovações que a transmissão de energia elétrica em larga escala passoua ser usada nos principais países industrializados, impulsionando um novo surto de inovações, como a lâmpada.

A eletricidade também encontrou seu uso na indústria, em que se destaca a indústria do cobre (matéria-prima necessária para conduzir a energia) e do alumínio. Bernal (1953, apud FREEMAN e SOETE, 2008) ressalta a eletricidade e a química como as duas áreas em que a pesquisa científica começou a estar diretamente relacionada ao desenvolvimento industrial. Neste período cabe destacar também as máquinas elétricas, mais modernas e superiores que as máquinas a vapor. Elas mudaram o funcionamento de diversos serviços e de muitas indústrias de transformação, além de exigir uma nova infraestrutura e uma nova regulação, seja por meio de uma legislação específica, de padrões e investimentos próprios, seja pela criação de entidades públicas e privadas voltadas a esta nova tecnologia (WEBER, 1922 apud FREEMAN e SOETE, 2008).

Essas novas tecnologias geraram mudanças em todo o sistema produtivo - surgiram os administradores profissionais e houve a padronização de informações e procedimentos e de toda a estrutura socioeconômica. Elas também impulsionaram outras inovações. Além desses novos conjuntos, Mowery e Rosenberg (2005) destacam o motor de combustão interna como uma das inovações mais importantes do período, desenvolvido no início do século XX e que se tornou o pivô da indústria automobilística; surge então a Era do Óleo, do Automóvel e da Produção em Massa.

De acordo com Mowery e Rosenberg (2005), embora o automóvel seja um invento europeu, logo se transformou em um produto de grande importância nos Estados Unidos. O desenvolvimento do automóvel foi motivado pela grande e acessível oferta de combustíveis e pela forte demanda. Schmookler (1962, apud MOWERY e ROSENBERG, 2005), por seu turno, afirma que o automóvel chegou mais em razão de mudanças econômicas e sociais do que das transformações tecnológicas em si.

Além do automóvel, a indústria automobilística foi importante também ao inovar implantando novos processos produtivos. Um destes processos foi a linha de produção. Popularizada por Henry Ford no início do século XX, este modelo tornou-se muito difundido, pois trazia altas taxas de produção a baixos custos.Castells $(2006$, p.75) complementa esta afirmação ao comentar que "foi o motor elétrico que tanto possíbilitou quanto introduziu a organização do trabalho em larga escala nas fábricas industriais."

A hegemonia norte-americana em várias áreas se deu basicamente em razão do investimento público, do papel da universidade na pesquisa e do interesse das grandes empresas em se manterem competitivas (FREEMAN e SOETE, 2008).

Com relação aos paradigmas tecnoeconômicos desses dois períodos, Perez (2009) menciona que a Era do Aço, da Eletricidade e da Engenharia Pesada trouxe ao mercado as gigantescas estruturas; economias de integração vertical; energia elétrica para a indústria; a ciência como força produtiva; rede mundial e dos impérios, incluindo os cartéis; padronização universal; contabilidade 
de custos para o controle e eficiência; grande escala do poder de mercado, entre outros. Já com relação à Era do Óleo, do Automóvel e da Produção em Massa, a autora destaca a produção em massa e o mercado de massa; economias de escala - volume de produto e mercado, integração horizontal; normalização dos produtos; intensidade energética, à base de óleo; materiais sintéticos; especialização funcional, pirâmides hierárquicas; centralização, suburbanização dos centros metropolitanos; poderes nacionais, acordos e confrontos mundiais.

Com relação às mudanças na sociedade, é possível afirmar que esses dois períodos apresentaram mudanças radicais no modo de vida e cultura da população, não só norte- americana como de todo o mundo. A eletricidade revolucionou os hábitos e o estilo de vida das pessoas. Quanto à indústria automobilística, Mowery e Rosenberg (2005) afirmam que o carro mudou o ritmo da vida urbana, transferindo muitos moradores dos grandes centros para os subúrbios. A facilidade de transporte fomentou outras atividades, como o turismo. Neste período surge uma necessidade maior de consumo, incentivada pelas grandes empresas, e o "American Life" passa a ser um padrão de vida para pessoas no mundo todo.

Quando se transfere essa nova realidade ao turismo, tema em pauta neste estudo, é possível afirmar que as inovações geradas nesse período também foram importantes para esta atividade, que passou a utilizá-las em benefício dos viajantes. Sobre a energia elétrica, Cândido e Viera (2003) afirmam que esta passou a ser empregada nos meios de hospedagem norte-americanos. O Hotel Everest, em Nova York, foi um empreendimento pioneiro ao utilizar iluminação elétrica parcial. Já o Sagamore Hotel, localizado no Lago George, também nos Estados Unidos, foi o primeiro a oferecer iluminação elétrica em todas as suas Unidades Habitacionais (CANDIDO e VIERA, 2003).

Trazendo uma visão geral sobre as transformações da atividade turística nesse período, Rejowski e Solha (2002, p. 71) propõem um recorte temporal, como segue:

- Início do Século (1900 a 1914) - crescimento tímido com as tendências assinaladas no final do século XIX;

- Primeira Guerra Mundial (1914 a 1919) - interrupção do fluxo turístico em face da deflagração e evolução do conflito;

- Período do Entre Guerras (1919 a 1939) - nova ascensão do turismo, interrompida parcialmente pela depressão econômica de Wall Street (crack da Bolsa de Valores de Nova York) em 1929-1931;

- Segunda Guerra Mundial (1939 a 1950) - paralisação do fluxo turístico mediante conflito de maiores proporções do que a anterior, e período de cinco anos pós-guerra para retomada do crescimento turístico;

- "Boom Turístico" ou Explosão do Turismo (1950 a 1973) - crescimento do fluxo turístico provocando a sua massificação [...]. 
Ainda de acordo com as autoras, o boom turístico, também conhecido como turismo massivo, ocorreu devido a fatores políticos, econômicos, educacionais, culturais, sociológicos, trabaIhistas, tais como a estabilidade política nos países europeus e americanos; o maior interesse em conhecer outros povos e civilizações; a necessidade crescente de descanso e lazer, e grandes avanços tecnológicos.

Gurría Di-Bella (1991) apresenta o automóvel como um elemento essencial para o desenvolvimento do turismo massivo. Para o autor, o uso do automóvel para viagens turísticas mudou a própria dinâmica do turismo, pois exigiu uma reestruturação na infraestrutura existente, incluindo a construção de rodovias e de equipamentos turísticos, como meios de hospedagem e ambientes gastronômicos nas estradas, para atender a esse novo público. Vale ressaltar que o ônibus foi outro veículo que passou a ser usado com fins turísticos. De acordo com Rejowski e Perussi (2008), em 1925 surgiram excursões turísticas utilizando o ônibus como meio de transporte. Hoje, é o veículo turístico mais popular no Brasil (PALHARES, 2003).

Há outras razões, contudo, que merecem ser mencionadas como fatores para o crescimento das viagens. Lickorish e Jenkins (2000) destacam o aumento maciço da riqueza e da renda disponível dos países. Barretto (1995, p. 54), por sua vez, ressalta o emprego do transporte aéreo para o uso civil, que logo se tornou o modal preferido dos turistas, "[...] pelo tempo ganho no deslocamento e pela introdução de tarifas turísticas e econômicas por avião". A autora cita ainda o aumento de empresas turísticas, como companhias aéreas e vários tipos de agências de turismo.

Diante do exposto, é possível constatar que as inovações se difundiram e criaram as condições para o desenvolvimento do turismo, mas também o crescimento e popularização da atividade turística foi um fator relevante na criação das condições para o desenvolvimento da nova revolução tecnológica que viria. Portanto, existe um processo sistêmico e de coevolução entre as inovações e o desenvolvimento da atividade de turismo.

\section{A Era da Informação e Telecomunicações}

No fim do século $X X$, as tecnologias da informação $(\mathrm{TI})$ começaram a mudar a sociedade como um todo. Elas tiveram seus primeiros vestígios a partir da década de 1940, quando surgiram as primeiras descobertas em eletrônica, desenvolvidas dentro dos laboratórios militares norte-americanos, mas somente na década de 1970 essas novas invenções se difundiram amplamente.

De acordo com Castells (2006, p.67), tecnologia da informação é "o conjunto convergente de tecnologias em microeletrônica, computação (software e hardware), telecomunicações/radiodifusão e optoeletrônica". Portanto, as três áreas que compõem essa revolução tecnológica são 
a microeletrônica, os computadores e as telecomunicações. O autor destaca ainda a engenharia genética como um dos motores responsáveis por essa nova onda, afirmativa esta contestada por outros autores, como Perez (2009), que acredita que esta nova área de pesquisa poderá fazer parte de uma nova revolução tecnológica. Freeman e Soete (2008, p.277), por seu turno, afirmam que "A introdução de computadores eletrônicos confiáveis e de baixo custo foi a inovação técnica mais revolucionária no século XX".

Esta revolução se iniciou nos Estados Unidos e sua grande difusão se deu, entre muitos aspectos, pelo investimento e incentivo do governo na pesquisa e desenvolvimento, e, posteriormente, pela queda crescente nos preços de seus bens em um curto espaço de tempo, algo que não tinha sido visto em outros períodos da história (FREEMAN e SOETE, 2008).

O avanço na difusão da microeletrônica ocorreu em 1971, quando a Intel inventou o microprocessador. Com este novo invento, a capacidade de processar informações poderia ser instalada em qualquer lugar. A extensão da transformação tecnológica foi muito rápida; a capacidade de memória e velocidade destes novos inventos aumentou drasticamente em pouquíssimo tempo. Esta tecnologia foi implantada em outros bens destinados ao dia a dia, como em fornos micro-ondas e automóveis(CASTELLS, 2006). Para o autor, a microeletrônica causou uma "revolução dentro da revolução" (p.79). Ele afirma que esta nova revolução tornou o mundo digital.

Além dos computadores pessoais (PC), os softwares também fizeram parte desta onda. As telecomunicações foram outra ferramenta importante neste processo, pela combinação de roteadores e computadores eletrônicos às novas tecnologias de transmissão.

A optoeletrônica - transmissão por fibra ótica e laser - e a transmissão por pacotes digitais promoveram um aumento sem precedentes na capacidade das linhas de transmissão (CASTELLS, 2006). O celular aparece, neste período, como uma inovação que surgiu beneficiada por essa nova tecnologia.

O conjunto dessas condições conduziu ao nascimento da Internet, que, segundo Castells (2006, p.82), "é talvez o mais revolucionário meio tecnológico da Era da Informação".

A Internet foi criada na década de 1960 pela Agência de Projetos de Pesquisa Avançada do Departamento de Defesa dos Estados Unidos como um sistema de comunicação invulnerável a ataques nucleares e como uma forma de se proteger da União Soviética. Com o desenvolvimento de outras tecnologias de comunicação, criou-se uma rede confiável que não necessitava obrigatoriamente de centros de controle. Mas foi só a partir de 1990, com a adoção do aplicativo World Wide Web (www) e a venda de navegadores de Internet, que esta ferramenta se tornou popular, acessível a todos, transformando-se em uma coqueluche global (CASTELLS, 2006).

Com relação à Biotecnologia, ou, como Castells (2006) denomina, "Tecnologias da Vida",esta surgiu no início da década de 1970, com a descoberta da combinação genética e a recombinação do DNA, base de toda a engenharia genética. No final da década de 1980 e durante os anos 1990, houve a revitalização da biotecnologia com ênfase na engenharia genética, como 
a clonagem genética. Hoje, os estudos relacionados a essa ciência são a terapia genética - inserção de genes saudáveis em indivíduo para o tratamento de doenças - e a profilaxia genética, que consiste na aplicação de meios para evitar as doenças genéticas ou a sua propagação; muitas destas pesquisas são patrocinadas pelo Estado (CASTELLS, 2006).

Castells (2006) explica que o desenvolvimento das Tecnologias de Informação e Comunicação (TICs) foi impulsionado pela dinâmica autônoma da descoberta e difusão tecnológica e queas TICs apresentaram efeitos sinérgicos entre todas as várias principais tecnologias. Com relação a esta afirmação, Freeman e Soete (2008) e Mowery e Rosenberg (2005) complementam que os governos exerceram um papel importante neste processo, seja financiando estas pesquisas ou realizando-as diretamente.

Apesar do papel decisivo do financiamento militar e dos mercados nos primeiros estágios da indústria eletrônica, da década de 1940 a 1960, o grande progresso tecnológico se deu no início dos anos 70, de certa forma, relacionado à cultura da liberdade, inovação individual e iniciativa empreendedora oriunda da cultura dos campi norte-americanos da década de 1960 (CASTELLS, 2006, p.43).

Cientistas e industriais de vários países tiveram um papel importante na descoberta e difusão dessas novas tecnologias. Mas, como se mencionou no início do texto, os Estados Unidos foram líderes no processo, principalmente a região denominada Vale do Silício, no norte do estado da Califórnia. Quando essas novas tecnologias chegaram a outros países houve a aplicação desta ferramenta em diversas áreas, produzindo diferentes inovações tecnológicas. Castells (2006) destaca, entretanto, que países como Japão, Alemanha, Inglaterra, entre outros, também possuem empreendimentos e inovações de vanguarda relacionada a essas novas tecnologias.

Independente das razões dessa nova onda, é possível afirmar que esse período trouxe mudanças geopolíticas, tecnológicas e sociais. Para Castells (2006, p.50), “A revolução da tecnologia da informação foi essencial para a implementação de um importante processo de reestruturação do sistema capitalista a partir da década de 80".

Com relação à afirmação anterior, é necessário destacar que essa revolução faz parte do desenvolvimento e renovação do sistema capitalista. “Essa nova estrutura social está associada ao surgimento de um novo modo de desenvolvimento, o informalismo, historicamente moldado pela reestruturação do modo capitalista de produção, no final do século XX." (CASTELLS, 2006, p.51). O autor complementa que o processo de reestruturação capitalista dos anos 1980 foi fundamental para a revolução da informação e que, sem a tecnologia da informação, o capitalismo global teria sido uma realidade muito limitada. 
Neste processo, houve a automação das tarefas, as experiências de usos e a reconfiguração das aplicações. A mente humana esteve diretamente ligada à produção e não foi apenas um elemento decisivo no sistema produtivo (CASTELLS, 2006). A forma como pensamos está exposta nos bens, serviços, produção material e intelectual etc. A tecnologia da informação, diferentemente das outras revoluções, conectou todo o mundo.

É importante ressaltar que as inovações só tiveram êxito por estarem envolvidas em um sistema que estimulava a pesquisa e desenvolvimento, além de contarem com apoio institucional e financeiro,o que possibilitou o desenvolvimento e difusão dessas tecnologias.

O paradigma tecnoeconômico dessa revolução é a informação, que se torna a matéria-prima do processo. Há maior penetrabilidade dos efeitos das novas tecnologias na vida do homem, o mundo hoje está inserido em redes, há maior flexibilidade e reconfiguração dos processos e a convergência de tecnologias específicas para um sistema altamente integrado. Com relação a esse paradigma é necessário destacar que o mesmo é abrangente, complexo e disposto em rede (CASTELLS, 2006).

Essa nova revolução também trouxe mudanças sociais e culturais para a sociedade. As relações de trabalho mudaram; hoje a mulher tem um papel importante no mercado de trabalho, o setor de serviços se mostra cada dia mais significativo economicamente, e diferentes tipos de profissionais e atividades surgiram. As relações sociais, entre amigos e familiares, também mudaram. A nova tecnologia uniu as pessoas, mas ao mesmo tempo também as afastou. O mundo se tornou mais rápido, mais dinâmico e mais exigente. (PEREZ, 2009; CASTELLS, 2006).

Quando se relaciona esta nova Era ao turismo, é preciso destacar que a tecnologia da informação, seja por meio dos diferentes softwares ou da própria Internet, passou a ser um instrumento vital para a atividade turística contemporânea (MOLETTA, 2001).

No âmbito do setor de viagens, o Global Distribution System (GDS), instituído na década de 1990, a partir do antigo Computerized Reservation System (CRS), é "[...] um sistema capaz de armazenar e integrar informações de companhias aéreas, hotéis, locadoras de automóveis em um único terminal ou computador, otimizando, dessa forma, a consulta e as reservas desses serviços [...]" (SANTOS e MURAD JR., 2008, p. 105). Portanto, é um serviço de informações e reservas que agiliza a operacionalização e a organização das viagens, podendo minimizar custos e aumentar o valor agregado das agências de turismo e outras empresas turísticas (MOLETTA, 2001).

Além das reservas, o setor de agências de turismo também possuem softwares administrativo-financeiros que dão apoio e suporte gerencial e operacional a estas empresas (PELIZZER, 2008). O autor ainda destaca que estes softwares auxiliam a "[...] redução efetiva dos custos, otimização do tempo e rentabilidade, competitividade, base do banco de dados, controles operacionais imediatos [...], bem como por prestador de serviços, por funcionário, por departamento etc." (p. 83). 
A hotelaria também possui softwares específicos para suas atividades. Cândido e Viera (2003) explicam que estes programas são divididos em módulos que podem estar integrados e que atendem às necessidades operacionais e gerenciais dos meios de hospedagem, facilitando, assim, sua gestão.

Os softwares, contudo, não foram a única inovação trazida para a atividade turística. A Internet mostrou ser uma ferramenta importante neste novo paradigma, gerando mudanças no próprio perfil do turista, e levando as empresas a repensarem seus modelos de negócio (VICENTIN e HOPPEN, 2003). Ela mudou a maneira como as pessoas organizam suas próprias viagens. De acordo com Vicentin e Hoppen (2003, p. 7), com a Internet "o cliente pode planejar e programar a sua viagem para qualquer lugar do mundo sem sair de casa". Ela facilitou o acesso às informações, o que tornou possível, ao turista, sem intermédio de um agente de viagens,

[...] realizar reservas de passagens aéreas e hotéis, efetuar pagamentos, alugar veículos, verificar condições do tempo no destino, cotações de moedas, aprender sobre a história, geografia e cultura do local de destino e verificar a documentação requerida, ou seja, praticamente tudo que é necessário para uma viagem (VICENTIN e HOPPEN, 2003, p. 7).

Em face dessa nova realidade, há uma discussão muito grande sobre a interferência da Internet no mercado de viagens, bem como se ela representa uma oportunidade ou uma ameaça aos profissionais que trabalham com este segmento. Santos e Murad Jr. (2008, p. 112) explicam que "[...] a Internet não deve ser encarada como uma ameaça ao agente de viagens, mas sim como uma ferramenta essencial de trabalho". Tanto Santos e Murad Jr. (2008) como Moletta (2001) afirmam que a Internet é uma "realidade inevitável", e sublinham que as agências de turismo devem se adaptar a esse novo panorama.

Uma das formas de adaptação encontradas por muitos empreendimentos turísticos é a criação de seus próprios portais eletrônicos. Estes portais facilitam a comunicação da empresa com seus clientes, além de oferecer a oportunidade de realizar transações eletrônicas de bens e serviços (e-commerce) sem intermediários (SANTOS e MURAD JR., 2008). Para comprovar a importância desta nova ferramenta, de acordo com Moletta (2001) quase 30\% do comércio eletrônico do continente europeu é movimentado pelos portais eletrônicos de viagens.

As novas tecnologias também trouxeram desenvolvimento a outros segmentos do turismo. Segundo Moletta (2001), o setor de transportes igualmente se beneficiou na Era da Informação. Os trens de alta velocidade e a modernização de aeronaves e navios de cruzeiros, 
que utilizam avançadas tecnologias e sistemas computadorizados, são apenas alguns exemplos desse novo cenário (MOLETTA, 2001).

Diante do exposto, é possível destacar que as inovações deste período revolucionaram o setor de viagens mundial. Os softwares e a própria Internet facilitaram as atividades e controles operacionais das empresas turísticas. Além disso, a Internet também tornou-se uma ferramenta indispensável para a informação dos viajantes. As mudanças vivenciadas por este período foram mais rápidas, porém transformadoras. O setor turístico passou a ser mais integrado, mais dinâmica, e pronto para as próximas revoluções.

\section{Considerações finais}

Este estudo teve como objetivo apresentar um ensaio teórico sobre o desenvolvimento da inovação, relacionando-o com a atividade turística em nível mundial. A partir dos dados da pesquisa bibliográfica foi possível trazeruma abordagem histórica da inovação, destacando as cinco revoluções tecnológicas vivenciadas pelo homem sob a ótica de Perez (2009), a saber: Revolução Industrial; Era do Vapor e dos Trilhos de Ferro; Era do Aço, da Eletricidade, da Engenharia Pesada; Era do Óleo, do Automóvel e da Produção em Massa; e a Era da Informação e Telecomunicações. Em cada uma das seções, foram apresentados os panoramas macroambientais, principais inovações, seus paradigmas e contribuições para a atividade turística global.

A pesquisa permitiu observar ainda, tal como destacado por Perez (2004), de que modo as revoluções tecnológicas modificaram as práticasem cada um dos períodos destacados. Além disso, foi possível perceber que estas revoluções estiveram intimamente ligadas ao desenvolvimento da atividade turística, pois, mesmo que as inovações ocorridas em cada uma delas não tenham sido destinadas diretamenteao turismo, muitas dessas criações foram absorvidas e adaptadas ao setor, fazendo parte, hoje, do dia a dia da atividade.

Na Revolução Industrial e na Era do Vapor e dos Trilhos de Ferro, o trem - máquina que a princípio foi dimensionada apenas como uma forma mais prática de transporte - passou a ser utilizado como um modal turístico, transformando a atividade turística de um setor amador para uma atividade organizada e profissional. Ele foi o motor para o turismo moderno. Quanto à Era do Aço, da Eletricidade, da Engenharia Pesada, bem como à Era do Óleo, do Automóvel e da Produção em Massa,verificou-se que o uso da energia elétrica em estabelecimentos turísticos trouxe maior comodidade aos viajantes, e que o transporte rodoviário, seja por meio do automóvel ou do ônibus, impulsionou uma nova demanda de clientes, tendo sido um dos responsáveis pelo turismo de massa. Já a Era da Informação e Telecomunicações trouxe a tecnologia da informação como uma aliada para a organização do setor, assim como para o próprio turista, que teve mais acesso às 
informações, fomentando assim sua necessidade de explorar novos lugares e transformando-o em seu próprio agente de viagens.

Como se comentou, ainda vivemos na Era da Informação e Telecomunicações, eportanto ainda poderão ocorrer mudanças significativas nos próximos anos, e mesmo novas revoluções tecnológicas. Elas trarão novas tecnologias e serão capazes de quebrar paradigmas, mas só no futurose poderá saber de que forma estarão relacionadas à atividade turística.

Este estudo não teve o objetivo de concluir a discussão, e sim de acenar paraa importância de outros trabalhos que atentem a esta temática. De acordo com Hjalager (2010), ainda há muitas questões em aberto no campo da inovação em turismo, inclusive pela falta de estudos mais sistematizados sobre o tema. Tais questões deveriam, segundo ela, ser discutidas no âmbito de pesquisas qualitativas que tratem da trajetória e dos impactos da inovação nos empreendimentos turísticos, bem como das implicações das políticas de inovação na atividade como um todo. Assim, sugere-se que outros trabalhos envolvendo o assunto sejam desenvolvidos, principalmente por estarmos vivendo um momento de transição para um novo paradigma, havendo a necessidade de pensar o turismo nesta nova perspectiva. 


\section{Referências}

BARRETTO, Margarita. Manual de iniciação ao estudo do turismo. Campinas, SP: Papirus, 1995.

BOYER, Marc. História do turismo de massa. Trad. Viviane Ribeiro. Bauru, SP: EDUSC, 2003.

BRUNELLI, Mariana de Queiroz; MACEDO-SOARES, Diana L.V.A.; SILVA, Roberto Farias. Inovação e colaboração no turismo carioca: primeiras evidências empíricas. RBTUR, Revista Brasileira de Pesquisa em Turismo, v.6, n.3, 2012.

CANDIDO, Índio Cândido; VIERA, Elenara Viera. Gestão de hotéis: técnicas, operações e serviços. Caxias do Sul: Educs, 2003.

CASTELLS, Manuel. A sociedade em redes. A era da informação: economia, sociedade e cultura; v.1. Trad. Roneide Venâncio Majer e Jussara Simões. 6. ed. São Paulo: Paz e Terra, 2006.

$\mathrm{CHAl}$, Andreas. System of demand innovation and the evolution of British Resort tourism. In: DRUID Summer Conference, 2005.

FIGUEIREDO, Paulo N.; GOMES, Saulo; FARIAS, Roberto. Innovative technological capability in firms of the tourism sector: a study of the hotels in the city of Rio de Janeiro during the 19902008 period. Rev. Adm. Pública, v.44,n.5, Rio de Janeiro,Sept./Oct. 2010.

FREEMAN, Chris; SOETE, Luc. A economia da inovação industrial. Clássico da Inovação. Trad. André Luiz Sica de Campos e Janaína Oliveira Pamplona da Costa. Campinas, SP: Unicamp, 2008.

GALLOUJ, Faïz. Innovating in reverse: services and the reverse product cycle. European Journal of Innovation Management, v.1, n.3, p.123-138, 1998.

GURRÍA DI-BELLA, Manuel. Introducciónal turismo. México: Trillas, 1991.

HJALAGER, Anne-Mette. A review of innovation research in tourism. Tourism Management, v. 31, n. 1, p. 1 12, 2010.

. Repairing innovation defectiveness in tourism. Tourism Management, $n$. 23, p. 465-474, 2002.

IGNARRA, Luiz Renato. Fundamentos do turismo. São Paulo: Pioneira Thomson Learning, 2001.

KLEMENT, Claudia Fernanda Franceschi. Inovação em serviços: estudo de caso de uma organização da indústria hoteleira brasileira. Tese de Doutorado. Universidade de São Paulo - USP, 2007.

LANDES, David S. A riqueza e a pobreza das nações. São Paulo: Campus, 1998.

LICKORISH, Leonard J.; JENKINS, Carson L. Introdução ao Turismo. Rio de Janeiro: Campus/Elsevier, 2000.

MOKYR, Joel. The Lever of Riches: Technological Creativity and Economic Progress.USA: Oxford University Press, 1990. 
MOLETTA, Vania B. Florentino. Turismo: tendências e novas tecnologias. Porto Alegre: SEBRAE/ RS, 2001.

MOWERY, David C.; ROSENBERG, Nathan. Trajetórias da inovação: a mudança tecnológica nos Estados Unidos da América no século XX. Trad. Marcel Knobel. Campinas, SP: Unicamp, 2005.

OMT. Introdução ao turismo. São Paulo: Roca, 2001.

PALHARES, Guilherme Lohmann. Transportes turísticos. São Paulo: Aleph, 2003.

PELIZZER, Hilário Ângelo. Sistema de gerenciamento administativo-financeiro.. In: BRAGA, Débora Cordeiro. Agências de viagens e turismo: práticas de mercado. São Paulo: Campus, 2008. PEREZ, Carlota. Technological revolutions and Techno-economic paradigms.In: Working Paper in Technology Governance and Economic Dynamics - The Other Foundation, Norway and TallinnUniversity of Technology. Tallin, 2009. Revoluciones tecnológicas, câmbios de paradigmas y de marco socioinstitucional. In: ABOITES, J. e DUTRÉNIT G. Inovación, prendizaje y creación de capacidades tecnológicas. UniversidadAuntónoma Metropolitana. Unidade Xochimilco. México, 2004.

PETERS, Mike; PIKKEMAAT, Birgit (Eds.) Innovation in hospitality and tourism. New York: The Haworth Hospitality Press, 2005.

REJOWSKI, Mirian; PERUSSI, Regina Ferraz. Trajetória das agências de turismo: apontamentos no mundo e no Brasil. In: BRAGA, Débora Cordeiro. Agências de viagens e turismo: práticas de mercado. São Paulo: Campus, 2008.

REJOWSKI, Mirian; SOLHA, Karina Toledo. Turismo em um cenário de mudanças. In: REJOWSKI, Mirian (Org.) Turismo no percurso do tempo. São Paulo: Aleph, 2002.

REJOWSKI, Mirian; YASOSHIMA, José Roberto; STIGLIANO, Beatriz Veroneze; SILVEIRA, Adalgiso Silva. Desenvolvimento do turismo moderno. In: REJOWSKI, Mirian (Org.) Turismo no percurso do tempo. São Paulo: Aleph, 2002.

ROSENBERG, Nathan. Por dentro da caixa preta: tecnologia e economia. Clássico da Inovação.

Trad. José Emílio Maiorino. Campinas, SP: Unicamp, 2006.

SANTOS, Célia Maria; MURAD JR., Eduardo Wanderley. Sistemas de reservas e e-commerce.

BRAGA, Débora Cordeiro. Agências de viagens e turismo: práticas de mercado. São Paulo: Campus, 2008.

SCHUMPETER, Joseph A. Capitalismo, socialismo e democracia. Ed. George Allen e Unwin Ltd., Trad. Ruy Jungmann. Rio de Janeiro: Fundo de Cultura, 1961.

SMITH, Adam. A riqueza das nações. São Paulo: Martins Fontes, 2003 [1777].

SMITH, Keith. Innovation as a Systemic Phenomenon: Rethinking the Role of Policy.In: Enterprise \& Innovation Management Studies, v. 1, n. 1,2000. 
VARGAS, Eduardo Raupp; ZAWISLAK, Paulo Antônio. Inovação em serviços: casos de hospitais porto-alegrenses. In: XXII Simpósio de Gestão da Inovação Tecnológica. Salvador, 2002.

VINCENTIN, Ivan Carlos; HOPPEN, Norberto. A internet no negócio de turismo no Brasil: utilização e perspectivas. REAd, Revista Eletrônica de Administração, ed. 31, v.9, n.1, jan-fev. 2003.

ZDEPSKI, Fabíola Bevervanço; CUNHA, SieglindeKindl; MENEZES, Vanessa de Oliveira; BULGACOV, Yára Lúcia Mazziotti. The dynamics of innovation in tourism: meaning the practice of tourism in Castrolanda, Parana, Brazil. In: LAEMOS 2012 - 4th Latin American and European Meeting on Organization Studies. March 27-30, Ajijic, Mexico, 2012. 